\title{
The nuclear receptors NUR77 and SF1 play additive roles with c-JUN through distinct elements on the mouse Star promoter
}

\author{
Luc $\mathrm{J}$ Martin ${ }^{1}$ and Jacques $\mathrm{J}$ Tremblay ${ }^{1,2}$ \\ ${ }^{1}$ Reproduction, Perinatal and Child Health, CHUQ Research Centre, CHUL Room T1-49, 2705 Laurier Boulevard, Quebec City, Quebec, Canada G1V 4G2 \\ ${ }^{2}$ Department of Obstetrics and Gynecology, Faculty of Medicine, Centre for Research in Biology of Reproduction, Université Laval, Quebec City, Quebec, Canada G1V 0A6 \\ (Correspondence should be addressed to J J Tremblay; Email: jacques-j.tremblay@crchul.ulaval.ca)
}

\begin{abstract}
The steroidogenic acute regulatory protein plays an essential role in steroid biosynthesis in steroidogenic cells. It is involved in the transport of cholesterol through the mitochondrial membrane where the first step of steroidogenesis occurs. Star gene expression in testicular Leydig cells is regulated by the pituitary LH through the cAMP signaling pathway. So far, several transcription factors have been implicated in the regulation of Star promoter activity in these cells. These include the nuclear receptors NUR77 and SF1, AP-1 family members (particularly c-JUN), GATA4, C/EBP $\beta$, DLX5/6, and CREB. Some of these factors were also shown to act in a cooperative manner to further enhance Star promoter activity. Here, we report that NUR77 and c-JUN have additive effects on the Star promoter. These effects were abolished only when both elements, NUR77 at $-95 \mathrm{bp}$ and AP-1 at $-78 \mathrm{bp}$, were mutated. Consistent with this, in vitro co-immunoprecipitation revealed that NUR77 and c-JUN interact and that this interaction is mediated through part of the ligand binding domain of NUR77. Furthermore, we found that SF1 could cooperate with C-JUN on the mouse Star promoter but this cooperation involved different regulatory elements. Collectively, our data not only provide new insights into the molecular mechanisms that control mouse Star transcription in Leydig cells but also reveal a novel mechanism for the regulation of NR4A1-dependent genes in tissues where NUR77 and c-JUN factors are co-expressed.
\end{abstract}

Journal of Molecular Endocrinology (2009) 42, 119-129

\section{Introduction}

The steroidogenic acute regulatory protein (STAR) plays a crucial role in the regulation of steroid biosynthesis by transporting cholesterol from the outer to the inner membrane of the mitochondria (reviewed in Manna et al. 2003a), an essential step in the initiation of steroidogenesis. In Leydig cells, the main steroidogenic cell within the mammalian testis, Star gene expression and steroidogenesis are mainly regulated by the pituitary LH that binds to its G-protein coupled receptor leading to production of cAMP and activation of cAMP-regulated pathways ultimately resulting in transcriptional activation.

Transcriptional regulation of the Star gene in steroidogenic cells was shown to require two groups of transcription factors: some already present in the cell activated by post-translational modifications, and others that must be de novo synthesized. In Leydig cells, Star transcription was shown to rely on several transcription factors belonging to the first group. These include SF1, LRH1, GATA4, C/EBP $\beta$, SREBP, SP1, DLX5/6, CREB/CREM, members of the AP-1 family (c-FOS and c-JUN), and DAX-1 (reviewed in Manna et al. 2003a). Regarding transcription factors belonging to the second group, we have recently identified the orphan nuclear receptor NUR77 (NR4A1) as a rapidly and strongly induced transcription factor that contributes to mouse Star transcription in Leydig cells in response to cAMP/forskolin stimulation (Martin et al. 2008).

The orphan nuclear receptor NUR77 (NGFI-B, NR4A1) is the founding member of a family that also comprises NURR1 (NR4A2) and NOR1 (NR4A3), all of which are characterized as immediate early response genes expressed in various tissues (Maxwell \& Muscat 2005), including in hormonally stimulated steroidogenic cells (Davis \& Lau 1994, Park et al. 2001, 2003, Song et al. 2001, Li et al. 2004, Martin \& Tremblay 2005, Martin et al. 2008). NUR77 transactivation potential is also enhanced by post-translational modifications (Davis et al. 1993, Hirata et al. 1993, Li \& Lau 1997, Martin et al. 2008) and/or modulation of its intracellular localization in response to certain stimuli (Klopotowska et al. 2005). NUR77 binds to DNA as a monomer to a regulatory element called NGFI-B response element (NBRE) similar to that recognized by the nuclear receptor steroidogenic factor 1 (SF1, Ad4BP, NR5A1; Wilson et al. 1993), a critical regulator of steroidogenic cell development and of many steroidogenic genes (Parker et al. 2002). Consistent with this, NUR77 and SF1 have been found to regulate a common set of genes involved in steroidogenesis in

DOI: 10.1677/JME-08-0095 Online version via http://www.endocrinology-journals.org 
Leydig cells (Zhang \& Mellon 1997, Bassett et al. 2004, Hong et al. 2004, Havelock et al. 2005, Martin \& Tremblay 2005), including Star (Martin et al. 2008). As for many other transcription factors regulating Star transcription, NUR77 is also expressed in non-steroidogenic tissues (Maxwell \& Muscat 2005). The tissue- and cell-specific expression as well as hormonal regulation of the Star gene in steroidogenic cells is believed to be the result of cooperations between transcription factors. Indeed, various studies of the Star promoter have reported protein-protein interactions between GATA4 and C/EBP $\beta$ (Tremblay et al. 2002), CREB, and SF1 (Manna et al. 2003b), SF1 and C/EBP $\beta$ (Reinhart et al. 1999), SP1 and SF1 (Sugawara et al. 2000), DLX5/6 and GATA4 (Nishida et al. 2008), and between c-JUN and SF1, GATA4, and C/EBP $\beta$ (Manna et al. 2004).

Transcription factors belonging to the AP-1 family are ubiquitously expressed and can be divided into two groups based on their amino acid similarity; the FOS (c-FOS, FRA-1, FRA-2, and FOSB) and the JUN (c-JUN, JUNB, and JUND) subfamilies (O'Shea et al. 1992). AP-1 family members have been shown to bind as dimers to specific DNA sequences located in the promoter of target genes (O'Shea et al. 1992). The FOS subfamily members must heterodimerize with JUN proteins, whereas JUN members can form either homoor heterodimers with any other AP-1 members.

Since the DNA binding elements for NUR77 and AP1 are only 12 bp apart in the mouse Star promoter from various species, we hypothesized that these two transcription factors might work together to regulate Star transcription in Leydig cells. Here, we report that all three NR4A family members (NUR77, NURR1, and NOR1) and c-JUN have additive effects on mouse Star transcription. Although, SF1 and LRH1 (NR5A family members) can also cooperate with c-JUN, we found that different regulatory elements are involved in the NR4A/c-JUN and the NR5A/c-JUN cooperation. Thus, our results provide new insights into the mechanisms of action of two closely related families of nuclear receptors in the regulation of the mouse Star promoter in Leydig cells.

\section{Materials and methods}

\section{Plasmids}

Luciferase reporter constructs harboring the $-902 \mathrm{bp}$ murine Star promoter, deletions of the Star promoter to $-193,-144,-121,-104$, and $-71 \mathrm{bp}$, and the -902 bp Star reporter construct with a mutation inactivating the SF1/NBRE element at $-95 \mathrm{bp}$ (CATCCTTGA to CATAATTGA) have been described previously (Tremblay \& Viger 2001, Martin et al. 2008). The $-902 \mathrm{bp}$ Star reporters containing either a mutation of the AP-1 element at -78 bp or a double mutation of the AP-1 and SF1/NBRE elements were generated by site-directed mutagenesis using the QuikChange XL mutagenesis kit (Stratagene, La Jolla, CA, USA) and the wild-type and mutated at SF1/NBRE Star reporter constructs as template and the following pair of oligos (mutations are italicized): AP-1 element at -78: sense: 5'-CCT TGA CCC TCT GCA CAA TGA GAG TTG ACT TTT TTA TCT CAA GTG-3', antisense: $5^{\prime}$ CAC TTG AGA TAA AAA AGT CAA CTCTCA TTG TGC AGA GGG TCA AGG-3'. The -104 bp Star reporter containing a mutation in the $-95 \mathrm{bp}$ SF1/NBRE element was generated by PCR using the mutated $-902 \mathrm{bp}$ as template. The $-104 \mathrm{bp}$ Star reporter containing mutations in both the $-95 \mathrm{bp}$ SF1/NBRE and $-45 \mathrm{bp}$ SF1 elements was generated by sitedirected mutagenesis (QuikChange XL mutagenesis kit, Stratagene) using the $-104 \mathrm{bp}$ Star reporter mutated in the $-95 \mathrm{bp} \mathrm{SF1/NBRE} \mathrm{and} \mathrm{the} \mathrm{following}$ oligos (mutations are italicized): sense: $5^{\prime}$-CTT TTT TAT CTC AAG TGA TGA TGC ATA CGT ATC CAC GGG AAG CAT TTA AGG CAG C-3', antisense: $5^{\prime}$-GCT GCC TTA AAT GCT TCC CGT GGA TACGTA TGC ATC ATC ACT TGA GAT AAA AAA G-3'. The mouse SF1 expression vector has been described previously (Tremblay \& Viger 2001). Rat NUR77, NOR1, and NURR1 expression vectors (Philips et al. 1997) were provided by Dr Jacques Drouin (Laboratoire de Génétique Moléculaire, Institut de Recherches Cliniques de Montréal, Montréal, Canada). The c-JUN, c-FOS, JUNB, JUND, FRA-1, and FRA-2 expression vectors (Teyssier et al. 2001) were obtained from Dr Dany Chalbos (Institut National de la Santé et de la Recherche Médicale, Endocrinologie Moléculaire et Cellulaire des Cancers, Montpellier, France).

Expression vectors for in vitro co-immunoprecipitation were generated by inserting the coding sequences (CDS) of the various transcription factors in the pRSETb vector (Invitrogen). For c-JUN, the CDS was obtained by PCR using mouse cDNA as template and the forward primer (5'-GCTCTAGAA TGA CTG CAA AGA TGG AAA CG- $3^{\prime}$ ) containing an Xba I cloning site (italicized) and the reverse primer (5'-CGGGTACCT CAA AAC GTT TGC AAC TGC TG-3' ${ }^{\prime}$ containing a Kpn I cloning site. The full-length NUR77 and a truncated protein lacking amino acids (aa) 1-225 were generated by PCR using rat cDNA as template, along with a common reverse primer containing a Bam HI (italicized) cloning site (5'-CGGGATCCT CAG AAA GAC AAG GTG TCC AT-3') and the following forward primers containing a $\mathrm{X} b a$ I cloning site: full length NUR77, 5'-GCTCTAGAA TGG ACC TGG CCA GCC CCG AG-3'; and 226 to 577 aa NUR77, 5'-GCTCTA GAG TGA CCT CCA CCA AGT CCC GG-3'. Vectors for other NUR77 deletion variants have been generated by restriction enzyme digestions followed by purification 
and ligation. NUR77 lacking aa 389 to 467 was obtained by internal deletion using $B s g$ I. NUR77 lacking aa 1-225 and 389-467, aa 1-225 and 426 to C-terminal, or aa 1-225 and 454 to C-terminal were obtained by internal deletion of the truncated NUR77 (lacking aa 1-225) using Bsg I, Sac I, and Pst I respectively.

\section{Cell culture and transfections}

Mouse MA-10 Leydig cells (Ascoli 1981), provided by Dr Mario Ascoli (University of Iowa, Iowa City, IA, USA), were grown and transfected as described in Martin et al. (2008).

\section{Protein purification and western blots}

Mouse MA-10 Leydig cells were incubated in serum-free medium containing $0.5 \mathrm{mM}(\mathrm{Bu})_{2} \mathrm{cAMP}$ for times ranging from 0 to $6 \mathrm{~h}$. MA-10 cells were then rinsed twice with ice cold PBS and harvested for nuclear protein extractions. Nuclear proteins were prepared by the procedure outlined by Schreiber et al. (1989). Protein concentrations were estimated using standard Bradford assay. Twenty microgram nuclear proteins were boiled for $10 \mathrm{~min}$ in a denaturing loading buffer, fractionated by SDS-PAGE, and transferred onto Polyvinylidene Fluoride (PVDF) membrane (Millipore, Billerica, MA, USA). Immunodetection was performed using an avidin-biotin approach according to the manufacturer's instructions (Vector Laboratories Inc., Ontario, Canada). Detections of NUR77, SF1, LRH1, c-JUN, c-FOS, STAR, and $\alpha$-TUBULIN were performed using a monoclonal anti-NUR77 antibody (1:500 dilution; BD Biosciences Pharmingen, San Diego, CA, USA), an anti-SF1 polyclonal antiserum (1:5000 dilution; kindly provided by Ken-Ichirou Morohashi, National Institute for Basic Biology, Japan), an antiLRH1 polyclonal antiserum (H-75X, 1:2000 dilution; Santa Cruz Biotechnologies, Santa Cruz, CA, USA), an anti-c-JUN polyclonal antiserum (N, 1:200 dilution; Santa Cruz Biotechnologies), an anti-c-FOS polyclonal antiserum (4, 1:200 dilution; Santa Cruz Biotechnologies), an anti-STAR polyclonal antiserum (FL285, 1:200 dilution; Santa Cruz Biotechnologies), and a monoclonal anti- $\alpha$-TUBULIN antibody (1:50 000 dilution; Sigma-Aldrich) respectively.

\section{Protein-protein interaction assays}

In vitro interactions were analyzed using NUR77, c-FOS or c-JUN full-length proteins and either ${ }^{35} \mathrm{~S}$-labeled fulllength SF1, c-FOS, c-JUN, or truncated NUR77 proteins. All proteins were obtained using the Quick Coupled TnT in vitro transcription/translation kit (Promega Corp, Madison, WI, USA). Proteins were incubated in $500 \mu$ l binding buffer (Tremblay et al. 2002) with $4 \mu \mathrm{g}$ NUR77, c-FOS, or c-JUN antisera for $24 \mathrm{~h}$ at $4{ }^{\circ} \mathrm{C}$ with agitation, followed by an additional $24 \mathrm{~h}$ in the presence of $20 \mu \mathrm{l}$ protein G-Sepharose beads (GE Healthcare, Baie d'Urfe, QC, Canada). Bound immunocomplexes were washed five times in binding buffer, resuspended in $20 \mu \mathrm{l} 2 \times$ SDS-loading buffer, and subjected to SDS-PAGE. Gel was soaked in $10 \%$ glycerol for $5 \mathrm{~min}$, and dried at $80^{\circ} \mathrm{C}$ for $90 \mathrm{~min}$. Proteins were visualized by autoradiography.

\section{Statistical analyses}

To identify significant differences between multiple groups, statistical analyses were done using a nonparametric Kruskal-Wallis one-way ANOVA followed by Mann-Whitney $U$-tests. Single comparisons between two experimental groups were done using the MannWhitney $U$-test. For all statistical analyses, $P<0.05$ was considered significant. All statistical analyses were done using the SigmaStat software package (Systat Software Inc., San Jose, CA, USA).

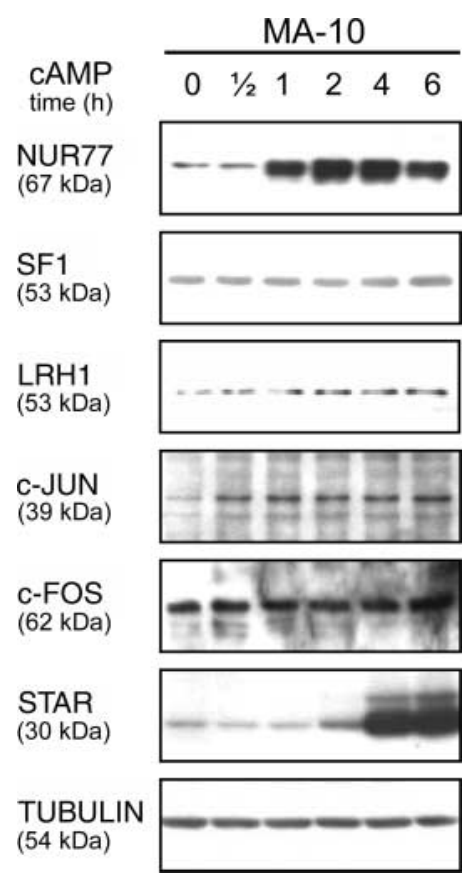

Figure $1 \mathrm{c}-\mathrm{JUN}$ and c-FOS are expressed in MA-10 Leydig cells. $\mathrm{MA}-10$ Leydig cells were treated with $(\mathrm{Bu})_{2} \mathrm{CAMP}(0.5 \mathrm{mM})$ for the indicated times. For detection of c-JUN, C-FOS, SF1, LRH1, and NUR77, nuclear extracts (since located in the nucleus) were prepared while whole cell extracts were used for STAR (since located in mitochondria). TUBULIN was used as a loading control. Western blots were done as described in Materials and methods. All experiments were repeated at least three times and produced identical results. 


\section{Results}

MA-10 Leydig cells have been shown to express c-JUN and c-FOS (Li et al. 1997, Manna et al. 2004). We tested whether expression of these two proteins in MA-10 Leydig cells is influenced by $(\mathrm{Bu})_{2}$ cAMP treatment. As shown in Fig. 1, we found that only c-JUN was upregulated in response to cAMP treatment and that

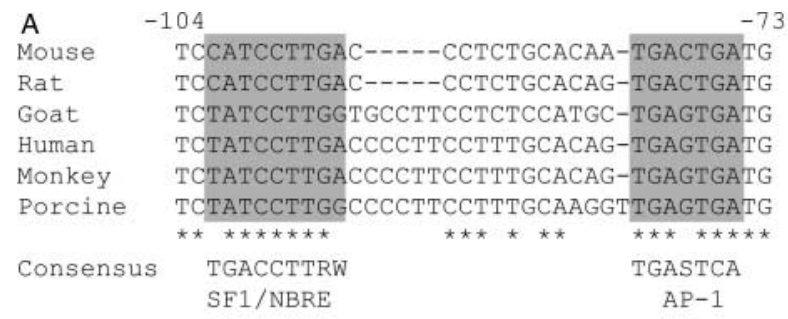

B
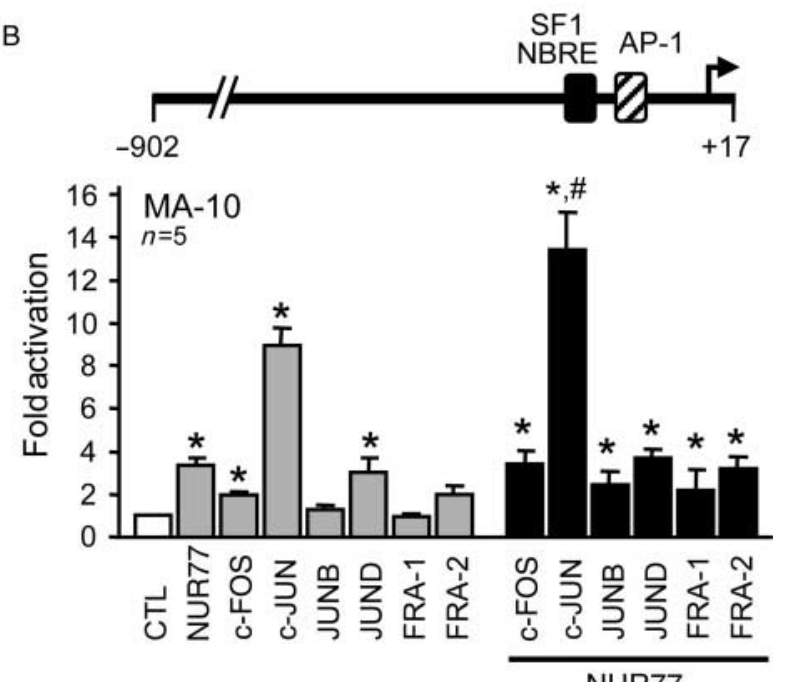

C
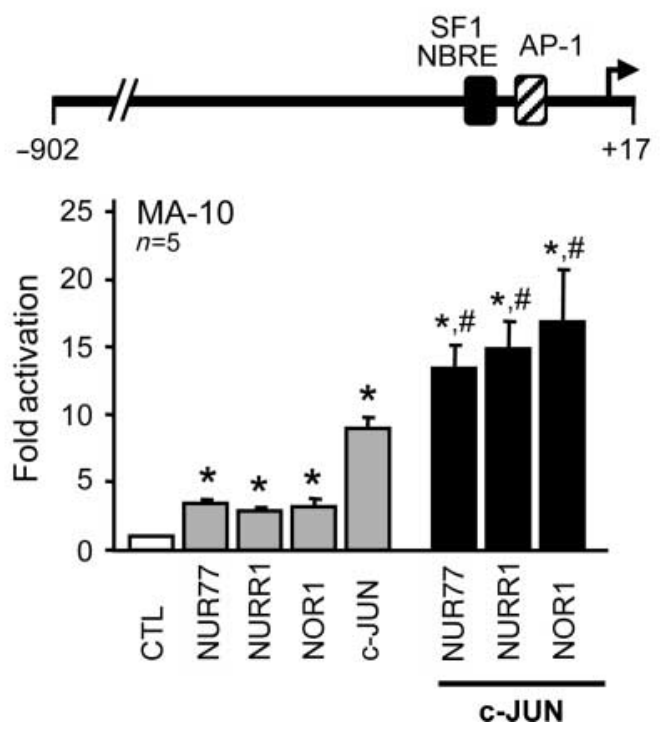

this increase occurred within $30 \mathrm{~min}$. As previously reported (Martin et al. 2008), NUR77 and STAR were both strongly upregulated in response to cAMP in MA-10 Leydig cells (Fig. 1). The same treatment led to a weak increase in the nuclear receptors SF1 and LRH1 (Fig. 1).

\section{NUR77 and c-JUN have additive effects on the mouse Star promoter}

Although, chromatin immunoprecipitation assay revealed that NUR77 is significantly recruited to the proximal region of the Star promoter (Martin \& Tremblay 2008, Martin et al. 2008), in vitro approaches such as EMSA showed a weak binding of NUR77 to the -95 bp SF1/NBRE element (Martin et al. 2008), suggesting that recruitment of NUR77 to the Star promoter might be mediated by interactions with other DNA-bound transcription factors. Moreover, the close proximity of the AP-1 ( $-78 \mathrm{bp})$ and SF1/NBRE ( $-95 \mathrm{bp}$ ) elements on the Star promoter (Fig. 2A) combined with the fact that AP-1 and NUR77 can individually regulate Star promoter activity in Leydig cells (Manna et al. 2004, Martin et al. 2008) raised the possibility that NUR77 and AP-1 family members might work together on the Star promoter. To test this, expression vectors encoding NUR77 and various AP-1 family members were transiently transfected in MA-10 Leydig cells along with a -902 bp mouse Star reporter. Consistent with previous reports (Wooton-Kee \& Clark 2000, Manna et al. 2004, Martin et al. 2008), both NUR77 and c-JUN individually activated the Star promoter 3.5 and 9 fold respectively (Fig. 2B). An

Figure 2 Additive effects of NR4A family members and c-JUN on the mouse Star promoter. (A) DNA sequence alignment of the -104 to -61 bp region of the Star promoter from different species highlighting the SF1/NBRE and AP-1 elements (grey shaded box). The sequence of the consensus SF1/NBRE and AP-1 elements is also shown. $\mathrm{W}=\mathrm{A}$ or $\mathrm{T}, \mathrm{R}=\mathrm{G}$ or $\mathrm{A}, \mathrm{S}=\mathrm{G}$ or $\mathrm{C}$. (B) C-JUN and NUR77 activate the Star promoter in an additive manner. MA-10 Leydig cells were co-transfected with a -902 to +17 bp mouse Star promoter construct along with an empty expression vector (CTL; open bar) or expression vectors for various AP-1 family members as indicated in the absence (grey bars) or presence (black bars) of an expression vector encoding NUR77. (C) NR4A family members and c-JUN have additive effects. MA-10 Leydig cells were co-transfected with a -902 to + 17 bp mouse Star promoter construct along with an empty expression vector (CTL; open bar) or expression vector for NR4A family members (NUR77, NURR1, NOR1 as indicated) in the absence (grey bars) or presence (black bars) of an expression vector encoding c-JUN. The number of experiments, each performed in duplicate, is indicated. Results are shown as fold activation over control ( \pm S.E.M). An asterisk $\left(^{*}\right)$ indicates a statistically significant difference from control (empty expression vector). \# indicates that the effect observed with a combination of transcription factors is statistically different than the effect of each factor individually. 
additive effect reaching 14 fold was observed when both factors were combined (Fig. 2B). Addition of c-FOS did not further enhance Star promoter activity (data not shown), suggesting that c-JUN homodimers are prevalent in Star transcriptional activation or that c-FOS is already sufficiently abundant in MA-10 Leydig cells (Fig. 1). As shown in Fig. 2C, other NR4A family members (NURR1 and NOR1) also had additive effects with c-JUN on the Star promoter.

To identify the binding elements required for these additive effects, transfections were performed using Star reporter constructs harboring mutations known to prevent NUR77 (Martin et al. 2008) and/or c-JUN (Manna et al. 2004) binding/transactivation. The NUR77/c-JUN additive effect was still observed on Star reporters harboring mutations in either the SF1/ NBRE (at - 95 bp) or AP-1 (at - 78 bp) element (Fig. 3). The absolute fold activation, however, was lower when the AP-1 element was mutated (Fig. 3). The NUR77/c-JUN additive effect was only abolished

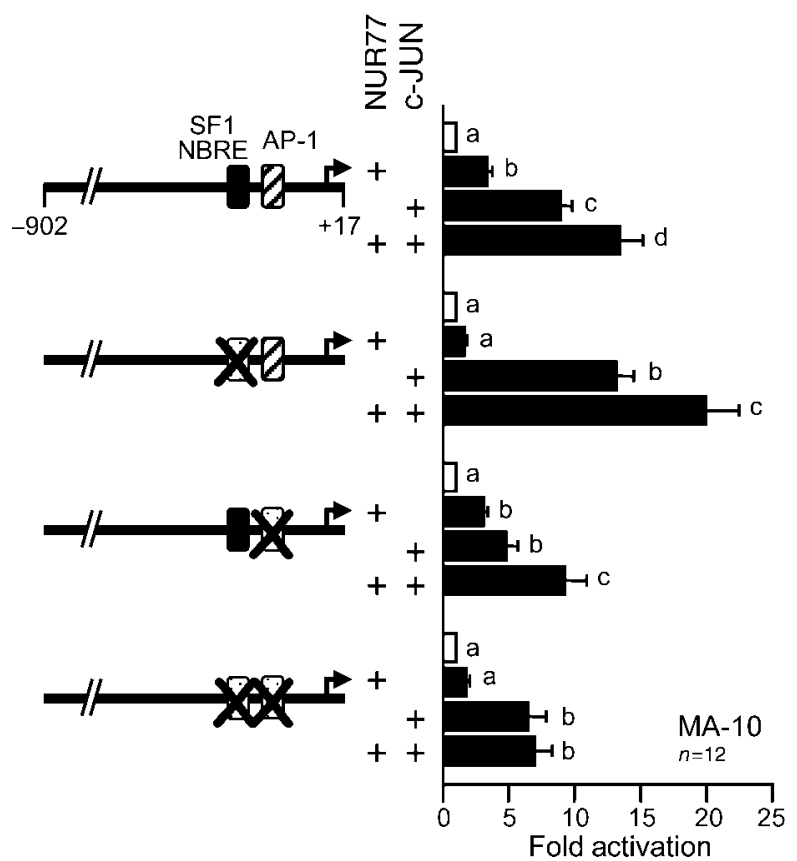

Figure 3 The NUR77/C-JUN additive effect requires either the SF1/NBRE element at $-95 \mathrm{bp}$ or the AP-1 element at $-78 \mathrm{bp}$. MA-10 Leydig cells were co-transfected with expression vectors for NUR77 and c-JUN as indicated by the plus sign, along with a wild type -902 to +17 bp Star reporter, a reporter harboring a two nucleotide mutation in the SF1/NBRE element at $-95 \mathrm{bp}$ (CCATCCTTGA to CCATAATTGA), a reporter containing a threenucleotide mutation in the AP-1 element at -78 bp (TGACTGATG to TGAGAGTTG), or a reporter containing mutations in both elements ( $-95 \mathrm{bp}$ and $-78 \mathrm{bp}$ ). Mutated elements are represented by a large $X$. The number of experiments, each performed in duplicate, is indicated. Results are shown as fold activation over control ( \pm S.E.M). A different letter indicates a statistically significant difference. when both elements were mutated (Fig. 3). Residual c-JUN-dependent activation of the Star promoter constructs containing a mutated AP-1 element at $78 \mathrm{bp}$ might be attributed to the presence of other functional AP-1 elements within the $-902 \mathrm{bp}$ Star promoter fragment (Shea-Eaton et al. 2002). Therefore, the additive effect of NUR77/c-JUN requires an intact binding site for one of the factors.

\section{NUR77 physically interacts with c-JUN in vitro}

The fact that an intact SF1/NBRE or AP-1 element is sufficient to sustain the NUR77/AP-1 additive effect suggests that the two factors might interact. To assess this possibility, co-immunoprecipitation using ${ }^{35} \mathrm{~S}-$ labeled in vitro translated proteins was performed. As shown in Fig. 4A, NUR77 physically interacts with c-JUN (lane 6) but not with c-FOS (lane 4). Co-immunoprecipitation of NUR77 and SF1 (Fig. 4A, lane 2) was used as a negative control since these nuclear receptors were

\section{A}

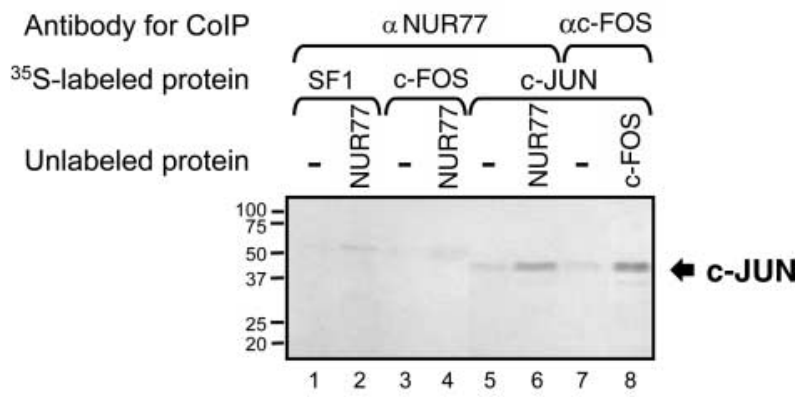

B

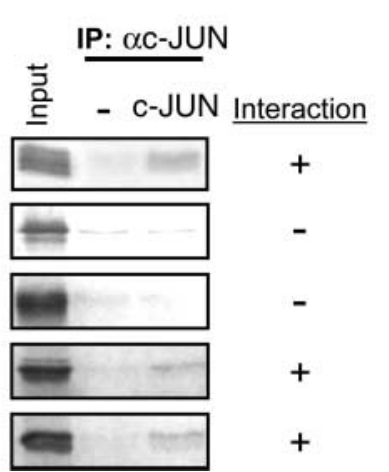

Figure 4 NUR77 physically interacts with c-JUN through its LBD. (A) NUR77 physically interacts with c-JUN in in vitro co-immunoprecipitation. In vitro produced ${ }^{35} \mathrm{~S}$-labeled and unlabeled proteins were mixed, immunoprecipitated using a NUR77 or C-FOS antibody as indicated, and subjected to SDS-PAGE followed by proteins visualization by autoradiography. (B) Protein-protein interaction between NUR77 and c-JUN is mediated by NUR77 LBD. In vitro co-immunoprecipitation using various deletion constructs of NUR77 were performed as described above. Positive c-JUN/NUR77 interactions are indicated on the right (plus and minus signs). Results are representative of three independent experiments. 
previously shown not to directly interact (Hong et al. 2004). Interaction between c-FOS and c-JUN (Fig. 4A, lane 8) served as a positive control (Kouzarides \& Ziff 1988). Taken together, our results indicate that NUR77 physically interacts with c-JUN in a protein complex that contributes to Star transcriptional regulation.

The same approach was next used with various truncated NUR77 proteins and the full length c-JUN to map the region of NUR77 involved in the interaction. As reported in Fig. 4B, we found that the region between aa 388 and 425 of NUR77 which contains the N-terminal portion of the ligand binding domain (LBD) was essential for the interaction with c-JUN in this in vitro protein-protein interaction assay.

\section{SF1 and LRH1 cooperate with c-JUN on the Star promoter}

In addition to NUR77 (this study), c-JUN has recently been reported to cooperate with the nuclear receptor $\mathrm{SF} 1$ to regulate human CYP11A1 promoter activity in steroidogenic cells (Guo et al. 2007). SF1 was also found to directly interact with c-JUN in a mammalian double-hybrid system (Manna et al. 2004). Since SF1 is an essential regulator of Star expression in Leydig cells, we tested the possibility that SF1 and c-JUN might work together on the mouse Star promoter. As shown in Fig. 5A, we found that SF1 and c-JUN can each activate the mouse Star promoter (2 and 11 fold respectively) and that the combination of both factors resulted in a transcriptional cooperation (20 fold). Similar results were obtained with LRH1 (FTF, NR5A2), another member of the NR5A family that has identical DNA binding properties to SF1 and is expressed in Leydig cells (Pezzi et al. 2004; Fig. 5B). Thus, although SF1 and LRH1 are weak activators of the Star promoter in MA-10 Leydig cells, they can also cooperate with c-JUN as do NR4A members (NUR77, NURR1, NOR1). The weak activation by SF1 and LRH1 may be explained by the already high levels of these factors in MA-10 cells (Zhang \& Mellon 1997, Daggett et al. 2000, Aesoy et al. 2002) since in heterologous cells that do not express SF1, SF1 can activate the Star promoter (Sugawara et al. 1996, Rust et al. 1998, Reinhart et al. 1999, and our unpublished data).

\section{NUR77 and SF1 have different site requirements for the cooperation with c-JUN}

The -95 bp element in the mouse Star promoter, that we identified as essential for NUR77 responsiveness (Martin et al. 2008) and important for the additive effects of NUR77 and c-JUN (Fig. 3), can also be bound by SF1/LRH1. In fact, NR5A members (SF1 and LRH1)
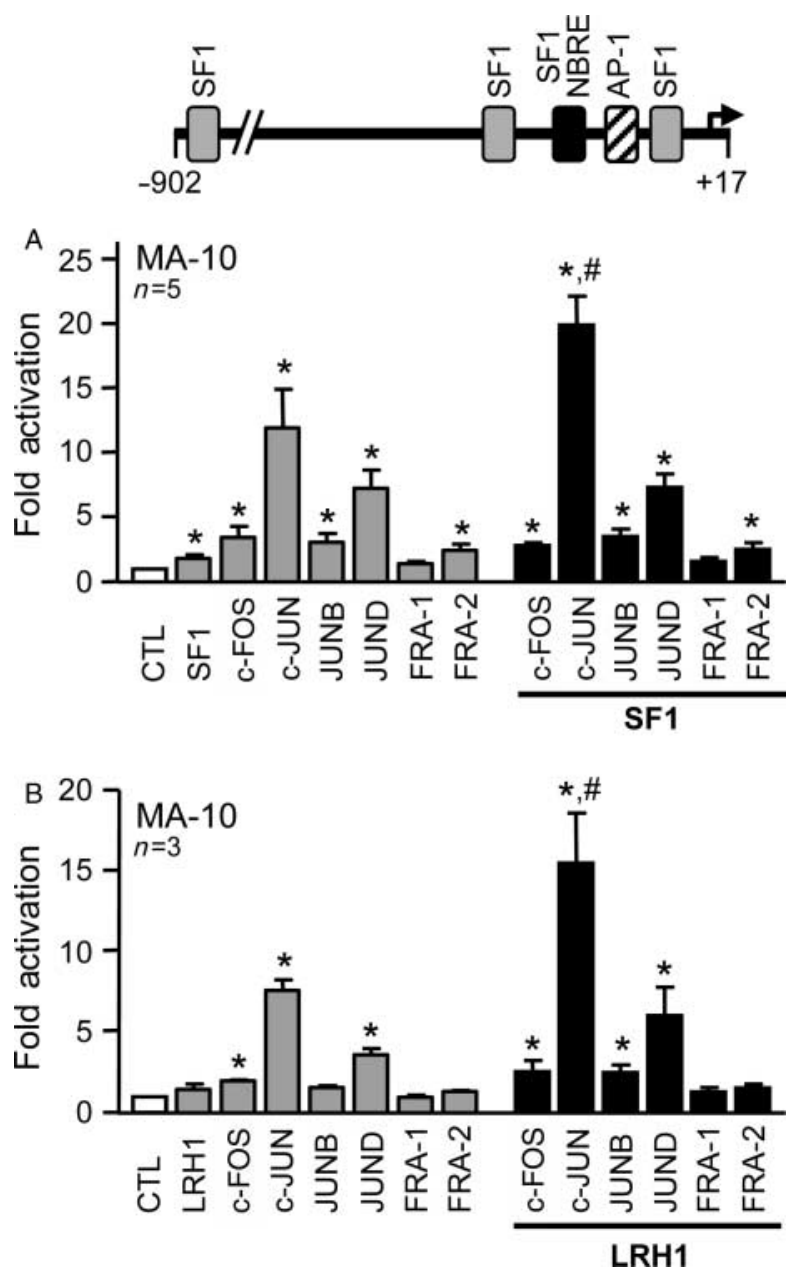

Figure 5 NR5A family members cooperate with c-JUN on the mouse Star promoter. MA-10 Leydig cells were co-transfected with a -902 to +17 bp mouse Star promoter construct along with an empty expression vector (CTL; open bar) or expression vectors for various AP-1 family members as indicated in the absence (grey bars) or presence (black bars) of an expression vector encoding SF1 (A) or LRH1 (B). The number of experiments, each performed in duplicate, is indicated. Results are shown as fold activation over control ( \pm s.E.M). An asterisk (*) indicates a statistically significant difference from control (empty expression vector). \# indicates that the effect observed with a combination of transcription factors is statistically different than the effect of each factor individually.

have a better affinity for this site than NR4A members (NUR77, NURR1, NOR1; Martin and Tremblay, unpublished data). We therefore tested whether this $-95 \mathrm{bp}$ element, along with the -78 bp AP-1 element, were required for the cooperation between c-JUN and NR5A family members. As shown in Fig. 6, a double mutation ( $-95 \mathrm{bp}$ SF1/NBRE and $-78 \mathrm{bp}$ AP-1), which completely abrogated the NUR77/c-JUN additive effect (Fig. 3), had no impact on the SF1/c-JUN and LRH1/ c-JUN cooperations on the mouse Star promoter. This 


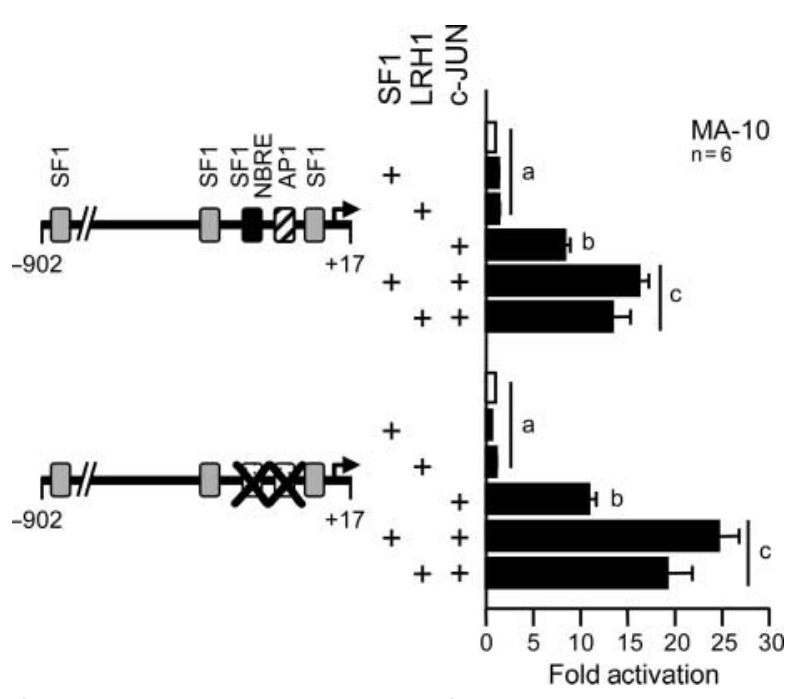

Figure 6 Distinct site requirements for the cooperation between c-JUN and NR5A members on the mouse Star promoter. MA-10 Leydig cells were co-transfected with an empty expression vector (open bars) or expression vectors for NR5A family members (SF1, LRH1) and c-JUN as indicated by the plus signs, along with a wild-type -902 to +17 bp Star reporter or a reporter containing mutations in both the -95 and -78 bp elements as described in Fig. 3. Mutated elements are represented by a large $X$. The number of experiments, each performed in duplicate, is indicated. Results are shown as fold activation over control ( \pm S.E.M). A different letter indicates a statistically significant difference.

indicates that another SF1/LRH1 element within the mouse Star promoter is involved in the NR5A/c-JUN cooperation.

In addition to the $-95 \mathrm{bp}$ element, the mouse Star promoter contains three other SF1 elements at -890 , -135 , and $-45 \mathrm{bp}$ (Caron et al. 1997). To identify which of these elements is sufficient for the cooperation with c-JUN, $5^{\prime}$-progressive deletion constructs of the Star promoter were transiently transfected in MA-10 Leydig cells. Deletion constructs from -902 to $-104 \mathrm{bp}$ which remove two SF1/LRH1 elements did not impair the SF1/c-JUN cooperation (Fig. 7A). Further deletion to -71 bp which removes the -95 bp SF1/NBRE and -78 bp AP-1 elements completely abrogated the synergy between SF1 and c-JUN. This indicates that the -45 bp SF1 element alone is not sufficient and that elements located within the $-104 \mathrm{bp}$ promoter fragment are required and sufficient for the SF1/c-JUN cooperation. To assess whether the $-95 \mathrm{bp} \mathrm{SF1/NBRE}$ element is implicated in this cooperation, the $-104 \mathrm{bp}$ Star reporter construct harboring a mutation in the -95 bp SF1/NBRE element was tested and found to still be cooperatively activated by SF1 and c-JUN (Fig. 7B). Collectively, these results indicate that the $-95 \mathrm{bp}$ SF1/NBRE element is not essential for the SF1/c-JUN cooperation and that the -78 bp AP-1 and -45 bp SF1 elements are both required and/or that

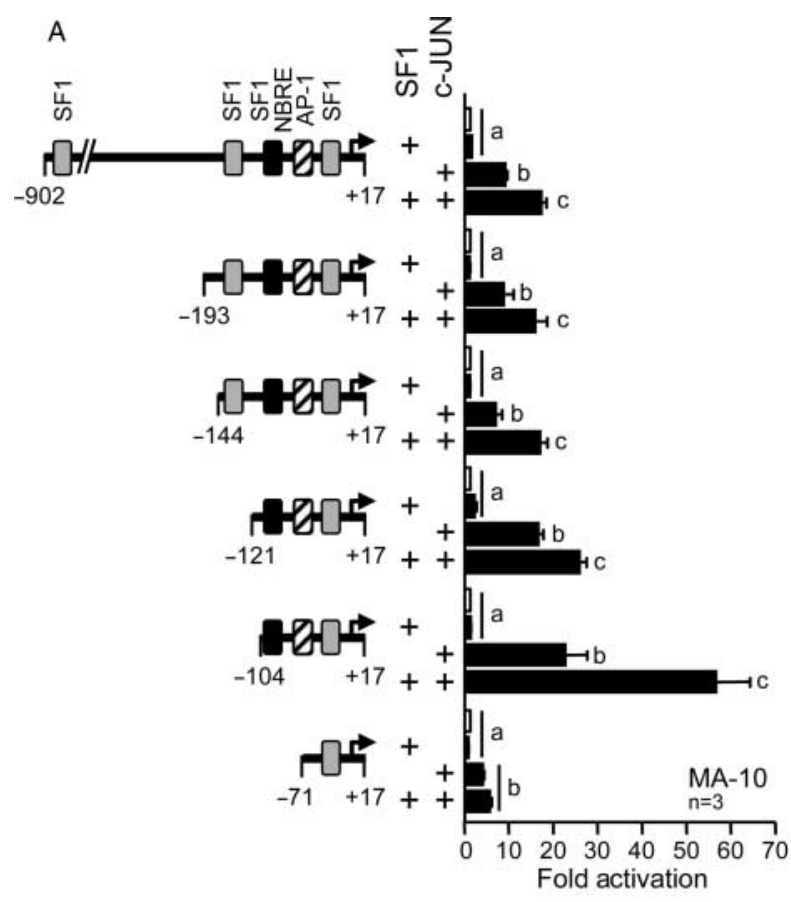

B

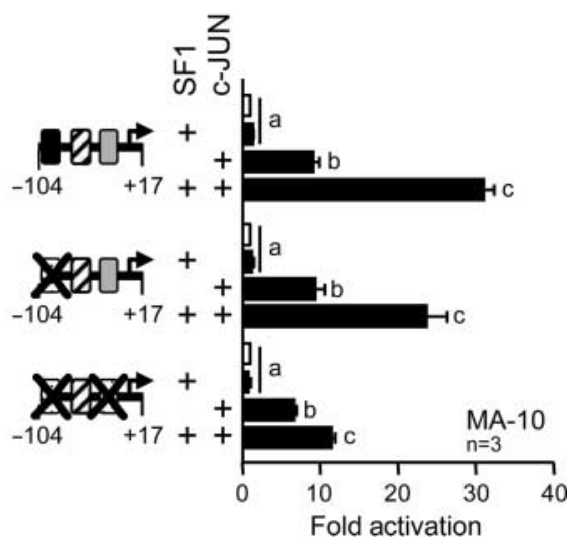

Figure 7 Mapping of the elements required for the SF1/c-JUN cooperation on the mouse Star promoter. MA-10 Leydig cells were co-transfected with an empty expression vector (open bars) or expression vectors for SF1 and c-JUN as indicated by the plus signs, along with (A) various $5^{\prime}$ progressive deletions of the mouse Star promoter or (B) - 104 bp Star reporter constructs harboring mutations in the SF1/NBRE element at -95 bp (CCATCCTTGA to CCATAATTGA) or in both the -95 bp SF1/NBRE, and the -45 bp SF1 (AAGGCT G to ATACGTA) elements. The mutated elements are depicted by large $X$. The number of experiments, each performed in duplicate, is indicated. Results are shown as fold activation over control ( \pm S.E.M). A different letter indicates a statistically significant difference.

the -78 bp AP-1 element alone is sufficient. To test this possibility, mutations were introduced in both the SF1/ NBRE at $-95 \mathrm{bp}$ and the SF1 at -45 bp elements in the context of the -104 bp Star reporter keeping only the -78 bp AP-1 element intact. This reporter was still cooperatively activated by SF1 and c-JUN (Fig. 7B). 


\section{Discussion}

Transcriptional regulation of the mouse Star gene is complex and yet the most important regulatory elements responsible for Star basal and hormoneinduced expression are located within a relatively short promoter region encompassing the first $150 \mathrm{bp}$ upstream of the transcription start site. More specifically, a $40 \mathrm{bp}$ region located between -105 and $-65 \mathrm{bp}$ is perhaps the most intricate since it was shown to contain overlapping binding sites for several transcription factors. For instance, an element at $-95 \mathrm{bp}$ of the mouse Star promoter was found to be important for basal and cAMP-responsiveness and shown to bind SF1 (Caron et al. 1997, Sugawara et al. 1997, Wooton-Kee \& Clark 2000). We recently reported that this $-95 \mathrm{bp}$ element is also essential to confer NUR77 responsiveness to the Star promoter (Martin et al. 2008). Less than $20 \mathrm{bp}$ away, at $-78 \mathrm{bp}$, is another species-conserved sequence (TGACTGA) found to be important for basal and cAMP stimulation of the mouse Star promoter (Wooton-Kee \& Clark 2000, Manna et al. 2004). This element closely resembles an AP-1 element (consensus: TGA(C/G) TCA, O'Shea et al. 1992) as well as a cAMP response element (CRE) for the binding of CREB/CREM family members (consensus: TGACGTCA Montminy et al. 1986). AP-1 family members and CREB were both found to bind this element (Wooton-Kee \& Clark 2000, Manna et al. 2002, 2004, Hiroi et al. 2004, Clem et al. 2005, Manna \& Stocco 2007).

How these transcription factors (SF1, NUR77, CREB, c-JUN, c-FOS) are recruited to this region of the Star promoter and how they contribute to the basal and cAMP responsiveness of Star expression remains to be fully elucidated. Recent studies, however, have provided some answers. For instance, it was reported that some transcription factors, such as CREB and AP-1, are constitutively associated with the proximal Star promoter in mouse Leydig cells and upon cAMP stimulation, CREB becomes rapidly phosphorylated leading to the recruitment of the CBP co-activator and to acetylation of histones (Hiroi et al. 2004, Clem et al. 2005). Furthermore, dominant negative forms of c-FOS, c-JUN, and CREB blunted cAMP responsiveness of the Star promoter confirming their implication in this process (Manna et al. 2002, 2004). On the other hand, binding of other transcription factors such as SF1 and GATA4 to the proximal Star promoter was shown to be increased following cAMP stimulation even though their protein levels remained unchanged (Hiroi et al. 2004, Martin \& Tremblay 2008). Finally, we found that cAMP stimulation of Leydig cells results in a rapid and strong induction in NUR77 protein levels that correlates with an increased association of NUR77 with the proximal Star promoter in an intact chromatin environment in primary Leydig cells and in MA-10 Leydig cells (Martin \& Tremblay 2008, Martin et al. 2008).

Because the binding motifs for NUR77, CREB, and AP-1 within the -105 to $-65 \mathrm{bp}$ region of the Star promoter are not perfect consensus sequences for these factors, it has been suggested that increased DNA binding and stability of these transcription factors might be achieved through protein-protein interactions. Consistent with this, there have been numerous reports of direct protein-protein interactions involving these transcription factors on the Star promoter in Leydig cells (Reinhart et al. 1999, Sugawara et al. 2000, Tremblay et al. 2002, Manna et al. $2003 b, 2004)$. In the present study, we have found that NUR77 and c-JUN have additive effects on the mouse Star promoter in Leydig cells. This finding may also have broader implications since NUR77 and c-JUN are co-expressed in a number of tissues where they could potentially act together to regulate gene transcription.

\section{In vitro interaction between NUR77 and c-JUN}

Using an in vitro co-immunoprecipitation approach, we provide evidence that NUR77 can physically interact with c-JUN. So far, in vivo co-immunoprecipitation assays using nuclear extracts from MA-10 Leydig cells to detect the presence of endogenous NUR77 and c-JUN together in a protein complex have been inconclusive (our unpublished data). This could be explained by inadequate epitope accessibility for the antisera tested in in vivo co-IP. Alternatively, the interaction between NUR77 and c-JUN might be weak and may be better observed with overexpressed proteins. Although, the NUR77/c-JUN protein interaction data need to be validated in a in vivo system, there is nonetheless evidence in the literature reporting that both NUR77 and c-JUN are associated with the proximal Star promoter region in vivo in Leydig cells (Manna \& Stocco 2008, Martin \& Tremblay 2008, Martin et al. 2008). Through our in vitro approach, we found that the region of NUR77 involved in the interaction with c-JUN was located within the LBD. This is unusual for NUR77 since most of its intra- and intermolecular interactions, including co-factor recruitment, described so far are mediated through the AF-1 domain (aa 50160; Wansa et al. 2002). It is therefore possible that the interaction of c-JUN with NUR77 LBD might alleviate the need for a ligand. In agreement with this, ligandindependent activation of nuclear receptors mediated by post-translational modifications (phosphorylation) or protein-protein interactions have been previously described (Tremblay et al. 1999a,b).

In addition to the c-JUN/NUR77 interaction reported herein, there has been only one other report of a protein-protein interaction involving NUR77 LBD 
and it is with protein kinase C (PKC; Kim et al. 2006). This is relevant to the present study since AP-1 factors, including c-JUN, typically mediate PKC signaling induced by phorbol-12-myristate-13-acetate (PMA; Angel et al. 1987). Furthermore, Leydig cells respond to PMA/PKC with increased phosphorylation of CREB and upregulation of Star transcription through regulatory elements located within the proximal Star promoter (Jo et al. 2005). Interestingly, CREB, which can bind to the -78 bp element of the Star promoter (Manna et al. 2002, Clem et al. 2005), was also reported to physically interact with NUR77 in another system (Mynard et al. 2004) raising the possibility that NUR77 and CREB might also interact in Leydig cells to activate Star transcription. We did not, however, observe any cooperation between CREB and NUR77 on the Star promoter in MA-10 Leydig cells (data not shown).

\section{SF1/c-JUN and NUR77/c-JUN cooperations involve different regulatory elements}

$\mathrm{SF} 1$, which is known to directly interact with c-JUN ( $\mathrm{Li}$ et al. 1999), was recently reported to transcriptionally cooperate with c-JUN on the human CYP11A1 promoter in steroidogenic cells (Guo et al. 2007). In the present study, we found that SF1, as well as LRH1, can cooperate with c-JUN to synergistically activate the Star promoter in Leydig cells. Consistent with the fact that the Star promoter contains multiple SF1 elements, we found that the SF1/c-JUN cooperation does not require the $-95 \mathrm{bp} \mathrm{SF} 1 / \mathrm{NBRE}$ element. Mutation of this element was previously reported to impair SF1- and NUR77-responsiveness/binding (Wooton-Kee \& Clark 2000, Martin et al. 2008). Here, we also found that this element also contributes to the additive effects between NUR77 and c-JUN. Thus, the NUR77/c-JUN and SF1/ c-JUN effects on the mouse Star promoter involve different regulatory elements. This suggests that the collaborations between c-JUN and NR5A (SF1 and LRH1) or NR4A (NUR77, NURR1, and NOR1) nuclear receptors are not mutually exclusive on the mouse Star promoter and may play complementary roles in Star basal and hormonally regulated expression.

Another mechanism by which NUR77 might contribute to Star transcription is by removing a transcriptional inhibitor. Indeed, NUR77 is known to directly interact with DAX-1 (Song et al. 2004), a nuclear receptor involved in the transcriptional repression of the Star gene (Zazopoulos et al. 1997). Therefore, the implication of NUR77 in Star promoter activation might happen via distinct mechanisms that are not mutually exclusive. These include direct recruitment to the promoter (Martin \& Tremblay 2008, Martin et al. 2008), interaction with other transcriptional activators such as c-JUN (this study), and removal of repressors such as DAX-1 from the Star promoter region.
Supporting this is the fact that the DAX-1-mediated repression of Star transcription is associated with NUR77 and SF1 (Manna et al. 2008).

In conclusion, our current findings along with data from the literature support the existence of a multiprotein complex containing NUR77, SF1, AP-1, PKC, GATA4, DLX5/6, C/EBP $\beta$, and CREB along with co-activators assembled on the proximal Star promoter. Because more than one factor can bind to the same element (e.g., NUR77 and SF1 at $-95 \mathrm{bp}$ and CREB and AP-1 at $-78 \mathrm{bp}$ ), this complex would be variable in composition depending on the absence or presence of a stimulus and on the nature of the stimulus itself. This would allow for a rapid integration of various signals ultimately leading to a fine-tuned regulation of Star transcription in Leydig cells.

\section{Declaration of interest}

The authors declare that there is no conflict of interest that would prejudice their impartiality.

\section{Funding}

L J Martin is supported by doctoral studentships from the Natural Sciences and Engineering Research Council of Canada and from Fonds de la recherche en santé du Québec. JJ Tremblay holds a New Investigator scholarship from the Canadian Institutes of Health Research (CIHR). This work was funded by grants from NSERC (262224-2003) and CIHR (MOP-81387) to J J Tremblay.

\section{Acknowledgements}

We would like to thank Drs Jacques Drouin, Dany Chalbos, and Mario Ascoli for generously providing expression plasmids and cell line used in this study.

\section{References}

Aesoy R, Mellgren G, Morohashi K \& Lund J 2002 Activation of cAMPdependent protein kinase increases the protein level of steroidogenic factor-1. Endocrinology 143 295-303.

Angel P, Imagawa M, Chiu R, Stein B, Imbra RJ, Rahmsdorf HJ, Jonat C, Herrlich P \& Karin M 1987 Phorbol ester-inducible genes contain a common cis element recognized by a TPA-modulated trans-acting factor. Cell 49 729-739.

Ascoli M 1981 Characterization of several clonal lines of cultured Leydig tumor cells: gonadotropin receptors and steroidogenic responses. Endocrinology 108 88-95.

Bassett MH, Suzuki T, Sasano H, De Vries CJ, Jimenez PT, Carr BR \& Rainey WE 2004 The orphan nuclear receptor NGFIB regulates transcription of $3 \beta$-hydroxysteroid dehydrogenase. Implications for the control of adrenal functional zonation. Journal of Biological Chemistry 279 37622-37630.

Caron KM, Ikeda Y, Soo SC, Stocco DM, Parker KL \& Clark BJ 1997 Characterization of the promoter region of the mouse gene encoding the steroidogenic acute regulatory protein. Molecular Endocrinology 11 138-147. 
Clem BF, Hudson EA \& Clark BJ 2005 Cyclic adenosine $3{ }^{\prime}, 5^{\prime}$ monophosphate (cAMP) enhances cAMP-responsive element binding (CREB) protein phosphorylation and phospho-CREB interaction with the mouse steroidogenic acute regulatory protein gene promoter. Endocrinology 146 1348-1356.

Daggett MA, Rice DA \& Heckert LL 2000 Expression of steroidogenic factor 1 in the testis requires an $\mathrm{E}$ box and CCAAT box in its promoter proximal region. Biology of Reproduction 62 670-679.

Davis IJ \& Lau LF 1994 Endocrine and neurogenic regulation of the orphan nuclear receptors Nur77 and Nurr-1 in the adrenal glands. Molecular and Cellular Biology 14 3469-3483.

Davis IJ, Hazel TG, Chen RH, Blenis J \& Lau LF 1993 Functional domains and phosphorylation of the orphan receptor Nur77. Molecular Endocrinology 7 953-964.

Guo IC, Huang CY, Wang CK \& Chung BC 2007 Activating protein-1 cooperates with steroidogenic factor- 1 to regulate $3^{\prime}, 5^{\prime}$-cyclic adenosine $5^{\prime}$-monophosphate-dependent human CYP11A1 transcription in vitro and in vivo. Endocrinology 148 1804-1812.

Havelock JC, Smith AL, Seely JB, Dooley CA, Rodgers RJ, Rainey WE \& Carr BR 2005 The NGFI-B family of transcription factors regulates

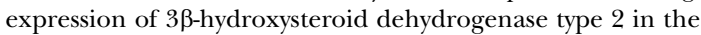
human ovary. Molecular Human Reproduction 11 79-85.

Hirata Y, Kiuchi K, Chen HC, Milbrandt J \& Guroff G 1993 The phosphorylation and DNA binding of the DNA-binding domain of the orphan nuclear receptor NGFI-B. Journal of Biological Chemistry 268 24808-24812.

Hiroi H, Christenson LK, Chang L, Sammel MD, Berger SL \& Strauss JF III 2004 Temporal and spatial changes in transcription factor binding and histone modifications at the steroidogenic acute regulatory protein (StAR) locus associated with StAR transcription. Molecular Endocrinology 18 791-806.

Hong CY, Park JH, Ahn RS, Im SY, Choi HS, Soh J, Mellon SH \& Lee K 2004 Molecular mechanism of suppression of testicular steroidogenesis by proinflammatory cytokine tumor necrosis factor alpha. Molecular and Cellular Biology 24 2593-2604.

Jo Y, King SR, Khan SA \& Stocco DM 2005 Involvement of protein kinase $\mathrm{C}$ and cyclic adenosine $3^{\prime}, 5^{\prime}$-monophosphate-dependent kinase in steroidogenic acute regulatory protein expression and steroid biosynthesis in Leydig cells. Biology of Reproduction 73 244-255.

Kim H, Kim BY, Soh JW, Cho EJ, Liu JO \& Youn HD 2006 A novel function of Nur77: physical and functional association with protein kinase C. Biochemical and Biophysical Research Communications 348 950-956.

Klopotowska D, Matuszyk J, Rapak A, Gidzinska B, Cebrat M, Ziolo E \& Strzadala L 2005 Transactivation activity of Nur77 discriminates between $\mathrm{Ca}^{2+}$ and cAMP signals. Neurochemistry International 46 305-312.

Kouzarides T \& Ziff E 1988 The role of the leucine zipper in the fosjun interaction. Nature 336 646-651.

Li Y \& Lau LF 1997 Adrenocorticotropic hormone regulates the activities of the orphan nuclear receptor Nur77 through modulation of phosphorylation. Endocrinology 138 4138-4146.

Li X, Hales KH, Watanabe G, Lee RJ, Pestell RG \& Hales DB 1997 The effect of tumor necrosis factor-alpha and cAMP on induction of AP1 activity in MA-10 tumor Leydig cells. Endocrine 6 317-324.

Li LA, Chiang EF, Chen JC, Hsu NC, Chen YJ \& Chung BC 1999 Function of steroidogenic factor 1 domains in nuclear localization, transactivation, and interaction with transcription factor TFIIB and c-Jun. Molecular Endocrinology 13 1588-1598.

Li W, Amri H, Huang H, Wu C \& Papadopoulos V 2004 Gene and protein profiling of the response of MA-10 Leydig tumor cells to human chorionic gonadotropin. Journal of Andrology $\mathbf{2 5}$ 900-913.

Manna PR \& Stocco DM 2007 Crosstalk of CREB and Fos/Jun on a single cis-element: transcriptional repression of the steroidogenic acute regulatory protein gene. Journal of Molecular Endocrinology 39 261-277.
Manna PR \& Stocco DM 2008 The role of c-Jun in the regulation of PKC-mediated StAR expression and steroidogenesis in mouse Leydig cells. Journal of Molecular Endocrinology 42 329-341.

Manna PR, Dyson MT, Eubank DW, Clark BJ, Lalli E, Sassone-Corsi P, Zeleznik AJ \& Stocco DM 2002 Regulation of steroidogenesis and the steroidogenic acute regulatory protein by a member of the cAMP response-element binding protein family. Molecular Endocrinology 16 184-199.

Manna PR, Wang XJ \& Stocco DM $2003 a$ Involvement of multiple transcription factors in the regulation of steroidogenic acute regulatory protein gene expression. Steroids 68 1125-1134.

Manna PR, Eubank DW, Lalli E, Sassone-Corsi P \& Stocco DM $2003 b$ Transcriptional regulation of the mouse steroidogenic acute regulatory protein gene by the cAMP response-element binding protein and steroidogenic factor 1. Journal of Molecular Endocrinology 30 381-397.

Manna PR, Eubank DW \& Stocco DM 2004 Assessment of the role of activator protein-1 on transcription of the mouse steroidogenic acute regulatory protein gene. Molecular Endocrinology 18 558-573.

Manna PR, Dyson MT, Jo Y \& Stocco DM 2008 Role of DAX-1 in PKAand PKC-mediated regulation of the steroidogenic acute regulatory protein expression in mouse Leydig tumor cells: mechanism of action. Endocrinology (doi: 10.1210/en.2008-0368).

Martin LJ \& Tremblay JJ 2005 The human 3ß-hydroxysteroid dehydrogenase $/ \Delta^{5}-\Delta^{4}$ isomerase type 2 promoter is a novel target for the immediate early orphan nuclear receptor NUR77 in steroidogenic cells. Endocrinology 146 861-869.

Martin LJ \& Tremblay JJ 2008 Glucocorticoids antagonize cAMPinduced StAR transcription in Leydig cells through the orphan nuclear receptor NUR77. Journal of Molecular Endocrinology 41 $165-175$.

Martin LJ, Boucher N, Brousseau C \& Tremblay JJ 2008 The orphan nuclear receptor NUR77 regulates hormone-induced StAR transcription in Leydig cells through a cooperation with CaMKI. Molecular Endocrinology 22 2021-2037.

Maxwell MA \& Muscat GE 2005 The NR4A subgroup: immediate early response genes with pleiotropic physiological roles. Nuclear Receptor Signaling 4 1-8.

Montminy MR, Sevarino KA, Wagner JA, Mandel G \& Goodman RH 1986 Identification of a cyclic-AMP-responsive element within the rat somatostatin gene. PNAS $\mathbf{8 3} 6682-6686$.

Mynard V, Latchoumanin O, Guignat L, vin-Leclerc J, Bertagna X, Barre B, Fagart J, Coqueret O \& Catelli MG 2004 Synergistic signaling by corticotropin-releasing hormone and leukemia inhibitory factor bridged by phosphorylated $3^{\prime}, 5^{\prime}$-cyclic adenosine monophosphate response element binding protein at the Nur response element (NurRE)-signal transducers and activators of transcription (STAT) element of the proopiomelanocortin promoter. Molecular Endocrinology 18 2997-3010.

Nishida H, Miyagawa S, Vieux-Rochas M, Morini M, Ogino Y, Suzuki K, Nakagata N, Choi HS, Levi G \& Yamada G 2008 Positive regulation of steroidogenic acute regulatory protein gene expression through the interaction between Dlx and GATA-4 for testicular steroidogenesis. Endocrinology 149 2090-2097.

O'Shea EK, Rutkowski R \& Kim PS 1992 Mechanism of specificity in the Fos-Jun oncoprotein heterodimer. Cell 68 699-708.

Park JI, Park HJ, Choi HS, Lee K, Lee WK \& Chun SY 2001 Gonadotropin regulation of NGFI-B messenger ribonucleic acid expression during ovarian follicle development in the rat. Endocrinology 142 3051-3059.

Park JI, Park HJ, Lee YI, Seo YM \& Chun SY 2003 Regulation of NGFI-B expression during the ovulatory process. Molecular and Cellular Endocrinology 202 25-29.

Parker KL, Rice DA, Lala DS, Ikeda Y, Luo X, Wong M, Bakke M, Zhao L, Frigeri C, Hanley NA et al. 2002 Steroidogenic factor 1: an essential mediator of endocrine development. Recent Progress in Hormone Research 57 19-36. 
Pezzi V, Sirianni R, Chimento A, Maggiolini M, Bourguiba S, Delalande C, Carreau S, Ando S, Simpson ER \& Clyne CD 2004 Differential expression of steroidogenic factor-1/adrenal 4 binding protein and liver receptor homolog-1 (LRH-1)/fetoprotein transcription factor in the rat testis: LRH-1 as a potential regulator of testicular aromatase expression. Endocrinology 145 2186-2196.

Philips A, Lesage S, Gingras R, Maira MH, GauthierY, Hugo P \& Drouin J 1997 Novel dimeric Nur77 signaling mechanism in endocrine and lymphoid cells. Molecular and Cellular Biology 17 5946-5951.

Reinhart AJ, Williams SC, Clark BJ \& Stocco DM 1999 SF-1 (steroidogenic factor-1) and C/EBP beta (CCAAT/enhancer binding protein-beta) cooperate to regulate the murine StAR (steroidogenic acute regulatory) promoter. Molecular Endocrinology 13 729-741.

Rust W, Stedronsky K, Tillmann G, Morley S, Walther N \& Ivell R 1998 The role of SF-1/Ad4BP in the control of the bovine gene for the steroidogenic acute regulatory (StAR) protein. Journal of Molecular Endocrinology 21 189-200.

Schreiber E, Matthias P, Muller MM \& Schaffner W 1989 Rapid detection of octamer binding proteins with 'mini-extracts', prepared from a small number of cells. Nucleic Acids Research 176419.

Shea-Eaton W, Sandhoff TW, Lopez D, Hales DB \& McLean MP 2002 Transcriptional repression of the rat steroidogenic acute regulatory (StAR) protein gene by the AP-1 family member c-Fos. Molecular and Cellular Endocrinology 188 161-170.

Song KH, Park JI, Lee MO, Soh J, Lee K \& Choi HS 2001 LH induces orphan nuclear receptor Nur77 gene expression in testicular Leydig cells. Endocrinology 142 5116-5123.

Song KH, Park YY, Park KC, Hong CY, Park JH, Shong M, Lee K \& Choi HS 2004 The atypical orphan nuclear receptor DAX-1 interacts with orphan nuclear receptor Nur77 and represses its transactivation. Molecular Endocrinology 18 1929-1940.

Sugawara T, Holt JA, Kiriakidou M \& Strauss JF III 1996 Steroidogenic factor 1-dependent promoter activity of the human steroidogenic acute regulatory protein (StAR) gene. Biochemistry 35 9052-9059.

Sugawara T, Kiriakidou M, McAllister JM, Kallen CB \& Strauss JF III 1997 Multiple steroidogenic factor 1 binding elements in the human steroidogenic acute regulatory protein gene $5^{\prime}$-flanking region are required for maximal promoter activity and cyclic AMP responsiveness. Biochemistry 36 7249-7255.

Sugawara T, Saito M \& Fujimoto S 2000 Sp1 and SF-1 interact and cooperate in the regulation of human steroidogenic acute regulatory protein gene expression. Endocrinology 141 2895-2903.
Teyssier C, Belguise K, Galtier F \& Chalbos D 2001 Characterization of the physical interaction between estrogen receptor alpha and JUN proteins. Journal of Biological Chemistry 276 36361-36369.

Tremblay JJ \& Viger RS 2001 GATA factors differentially activate multiple gonadal promoters through conserved GATA regulatory elements. Endocrinology 142 977-986.

Tremblay A, Tremblay GB, Labrie F \& Giguere V 1999 $a$ Ligandindependent recruitment of SRC-1 to estrogen receptor beta through phosphorylation of activation function AF-1. Molecular Cell 3 513-519.

Tremblay JJ, Marcil A, Gauthier Y \& Drouin J 1999 $b$ Ptx 1 regulates SF-1 activity by an interaction that mimics the role of the ligand-binding domain. EMBO Journal 18 3431-3441.

Tremblay JJ, Hamel F \& Viger RS 2002 Protein kinase A-dependent cooperation between GATA and C/EBP transcription factors regulates StAR promoter activity. Endocrinology 143 3935-3945.

Wansa KD, Harris JM \& Muscat GE 2002 The activation function-1 domain of Nur77/NR4A1 mediates trans-activation, cell specificity, and coactivator recruitment. Journal of Biological Chemistry 277 33001-33011.

Wilson TE, Fahrner TJ \& Milbrandt J 1993 The orphan receptors NGFI-B and steroidogenic factor 1 establish monomer binding as a third paradigm of nuclear receptor-DNA interaction. Molecular and Cellular Biology 13 5794-5804.

Wooton-Kee CR \& Clark BJ 2000 Steroidogenic factor-1 influences protein-deoxyribonucleic acid interactions within the cyclic adenosine 3,5-monophosphate-responsive regions of the murine steroidogenic acute regulatory protein gene. Endocrinology 141 13451355.

Zazopoulos E, Lallie E, Stocco DM \& Sassone-Corsi P 1997 DNA binding and transcriptional repression by DAX-1 blocks steroidogenesis. Nature 390 311-315.

Zhang P \& Mellon SH 1997 Multiple orphan nuclear receptors converge to regulate rat $\mathrm{P} 450 \mathrm{c} 17$ gene transcription: novel mechanisms for orphan nuclear receptor action. Molecular Endocrinology 11 891-904.

\section{Received in final form 8 October 2008 Accepted 5 November 2008} Made available online as an Accepted Preprint 5 November 2008 